\title{
CARACTERÍSTICAS PRODUTIVAS, ESTRUTURAIS E NUTRITIVAS DE GRAMÍNEAS TROPICAIS SOB PASTEJO
}

\author{
Lucas Guilherme Bulegon ${ }^{1}$, Deise Dalazen Castagnara ${ }^{2}$, Nivaldo Karvatte Júnior ${ }^{1}$, Paulo Sergio \\ Rabello de Oliveira ${ }^{1}$, Marcela Abbado Neres ${ }^{1}$ \\ ${ }^{1}$ Universidade Estadual do Oeste do Paraná - UNIOESTE. ${ }^{2}$ Universidade Federal do Pampa - UNIPAMPA. \\ Correspondência para: Lucas Guilherme Bulegon - lucas_bulegon@yahoo.com.br
}

\section{RESUMO}

Objetivou-se estudar as características produtivas, estruturais e nutricionais dos capins Urochloa ruziziensis, Urochloa brizantha cv. MG5 e Panicum maximum cvs. Áries e Mombaça sob pastejo. $\mathrm{O}$ experimento foi conduzido à campo sob o delineamento de blocos ao acaso com parcelas subdivididas no tempo, estudando-se as quatro gramíneas e dois períodos de crescimento das plantas 47 e 87 dias após a semeadura (DAS). Estudou-se a produção de matéria seca total, de folhas e colmos, e as proporções destes na forragem. Também foram avaliadas a altura de plantas, perfilhamento, diâmetro do colmo, número e comprimento de folhas, comprimento de colmos e relação folha/colmo, e os teores de proteína bruta, FDN, FDA e hemicelulose. A produção de matéria seca total, de folhas e colmos foi superior no segundo período de crescimento, com destaque para a elevada produção de matéria seca de folhas do capim Mombaça. As forrageiras apresentaram características estruturais diferenciadas que foram afetadas também pelos períodos de crescimento. $O$ teor de proteína bruta foi superior no capim Mombaça no segundo período de crescimento. Todas as forrageiras elevaram o teor de FDA no segundo período de crescimento. Em pastagens manejadas sob pastejo com intervalos de 40 dias, o capim Mombaça apresenta elevada produção de forragem com maior proporção de folhas, reduzido alongamento de colmos, e teor de proteína bruta superior.

Palavras-chave: Urochloa; forrageiras; Panicum maximum; proteína bruta

\section{PRODUCTION, STRUCTURAL AND NUTRITIONAL CHARACTERISTICS OF TROPICAL GRASSES UNDER GRAZING}

\begin{abstract}
This project aimed to study the productive, structural and nutritional characteristics of grasses Urochloa ruziziensis, Urochloa brizantha cv. MG5 and Panicum maximum cvs. Áries and Mombasa under grazing. The experiment was leaded to the field under the delimitation of random blocks with split-plot, studying the four grasses and two periods of plant growth, 47 e 87 days after the sowing (DAS). It was studied the production of total dry matter, of leaves and culms, and its proportions on the forage. It was also evaluated the plant height, tillering, culm diameter, leaves numbers and length, culm length, leaf/culm ratio, the content of crude protein, ADF, NDF and hemicellulose. The production of total dry matter, of leaves and culms was higher on the second period of growth, with emphasis on the high production of dry matter of leaves of the Mombasa grass. The forages had different structural characteristics that were also affected by the growth periods. The crude protein level was higher on the Mombasa grass on the second period of growth. All the forages had their ADF heightened on the second period of growth. In pastures managed under grazing with 40 days intervals, the Mombasa grass has high forage production with a higher proportion of leaves, reduced culm lengthening and higher crude protein content.
\end{abstract}

Keywords: Urochloa; forage; Panicum maximum; crude protein 


\section{INTRODUÇÃO}

O ecossistema de pastagens é complexo e seus componentes bióticos e abióticos interagem entre si de maneiras diferentes (DIFANTE et al., 2011). Em sistemas de pastejo têm-se de um lado o animal promovendo a desfolha, e do outro a planta, numa busca constante pela renovação da área foliar.

Para o entendimento das respostas das plantas à desfolha promovida através do pastejo, torna-se fundamental $\mathrm{o}$ conhecimento e estudo de parâmetros relacionados morfofisiologia das pastagens (DIFANTE et al., 2011), uma vez que o manejo pode definir potencialmente o crescimento e a produtividade das pastagens (SKONIESKI et al., 2011), alterando também o seu valor nutritivo.

A produtividade de pastagens pode ser estudada por meio da produção de matéria seca da parte aérea, podendo-se ainda estudar separadamente a produção de matéria seca de folhas e de colmos e as relações entre ambos. Os caracteres morfofisiológicos são estudados a partir de avaliações estruturais das plantas, enquanto o valor nutritivo, segundo Cano et al. (2004), pode ser estimado por meio da composição química da forragem. As respostas das plantas nos diferentes aspectos citados acima variam em função do meio e do manejo aplicado e da espécie forrageira em estudo (VELAZQUES et al., 2010).

O capim-braquiária destaca-se na pecuária brasileira ocupando extensas áreas (VIANA et al., 2011), enquanto as forrageiras da espécie Panicum maximum Jacq. são consideradas as mais importantes na produção de bovinos nas regiões de clima tropical e subtropical (MINGOTTE et al., 2011). No entanto, apesar da relevância dessas forrageiras, são escassos os resultados de pesquisa que contemplaram seu estudo comparativo em condições de pastejo, pois apesar de pertencerem à mesma espécie, algumas cultivares podem apresentar grandes diferenças morfológicas, produtivas e nutricionais entre si.

Nesse sentido, o presente trabalho teve como objetivo estudar as características produtivas, estruturais e nutritivas dos capins Urochloa ruziziensis, Urochloa brizantha cv. MG5 e Panicum maximum cvs. Áries e Mombaça sob pastejo.

\section{MATERIAL E MÉTODOS}

O experimento foi conduzido em condições de campo, na fazenda experimental "Professor Antônio Carlos dos Santos Pessoa", em área experimental do Centro de Ciências Agrárias da Universidade Estadual do Oeste Paraná - Campus Marechal Cândido Rondon, localizado na região Oeste 
do Paraná, latitude 24933'22'S e longitude 5403'24"W, com altitude aproximada de 393 m. O clima da região, segundo a classificação de Köppen, é do tipo Cfa, com clima subtropical úmido com temperaturas médias anuais variando entre $17{ }^{\circ} \mathrm{C}$ e 19 으 $\mathrm{e}$ precipitação média anual de $1500 \mathrm{~mm}$. Os dados climáticos do período experimental foram obtidos em estação climatológica automática localizada sob latitude 240 19’S,

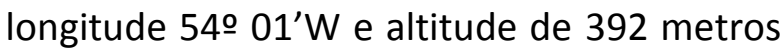
(Figura 1)

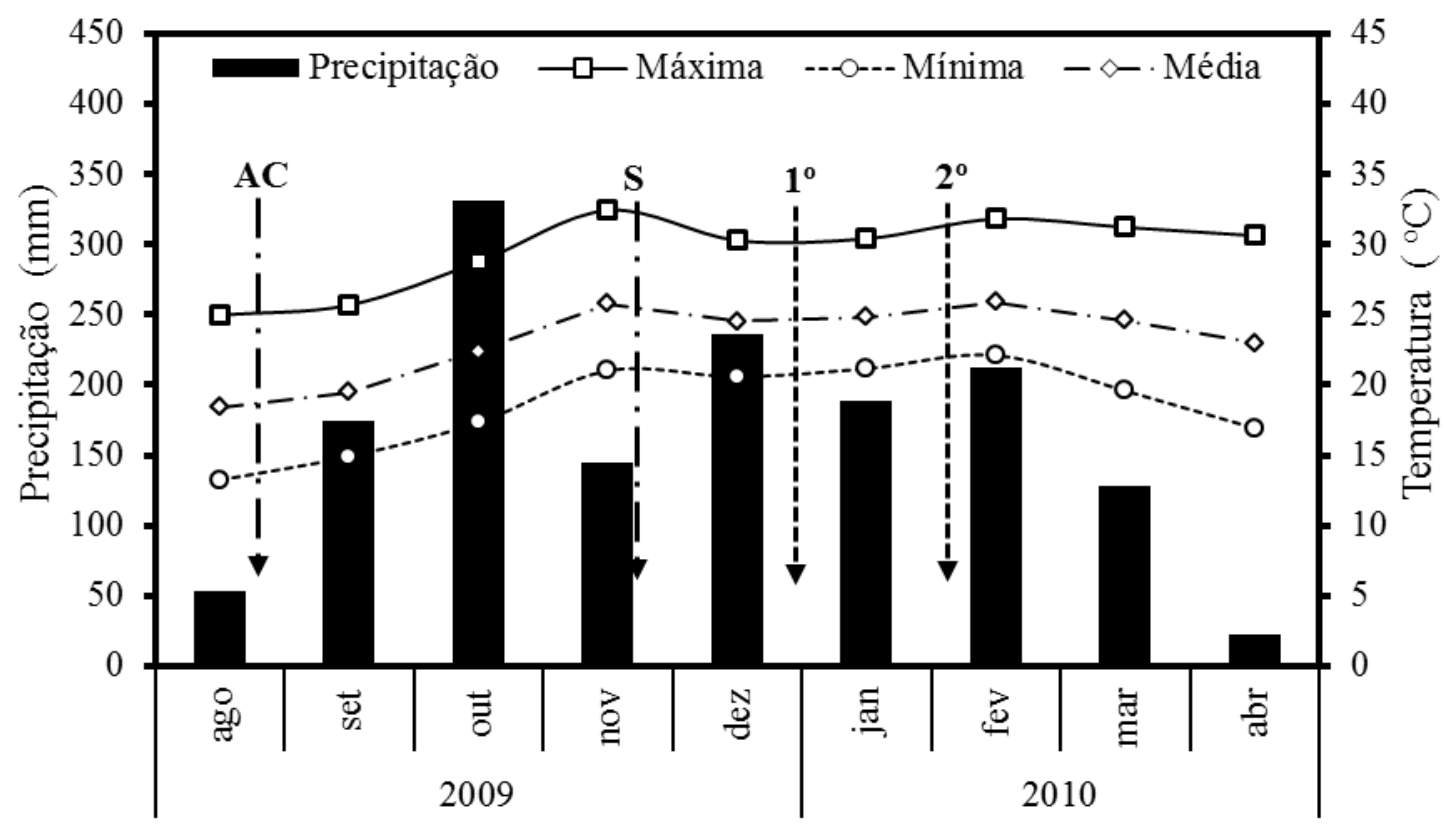

Figura 1. Médias mensais das temperaturas máxima, mínima e média e precipitação mensal acumulada durante o período experimental. AC: aplicação de calcário; S: semeadura, 1ㅇ e 2o: primeira e segunda amostragens com posterior pastejo.

Fonte: Estação Climatológica Automática do Núcleo de Estações Experimentais da Unioeste, Marechal Cândido Rondon- PR, 2009-2010.

O experimento foi implantado no campo sob o delineamento experimental de blocos ao acaso com quatro forrageiras tropicais (Urochloa ruziziensis, Urochloa brizantha cv. MG5 e Panicum maximum cvs. Áries e Mombaça) e cinco repetições, totalizando 20 unidades experimentais, representadas por parcelas com dimensões de $12 \times 8 \mathrm{~m}\left(96 \mathrm{~m}^{2}\right)$. As avaliações foram realizadas sob o delineamento de blocos ao acaso com parcelas subdivididas no tempo, com quatro forrageiras tropicais e dois tempos de avaliação [47 e 87 dias após a semeadura (DAS)].

Antes da implantação do experimento, em julho de 2009 foi realizada amostragem de solo para a caracterização química (Tabela 1), conforme recomendação de Silva (2009). O solo foi classificado como Latossolo Vermelho (EMBRAPA, 2006). Em agosto de 2009 foi realizada a correção do solo da área experimental com a aplicação de calcário 
dolomítico elevando a saturação por bases para $60 \%$. O calcário dolomítico foi distribuído à lanço, com posterior incorporação com auxílio de grade pesada acoplada ao trator, seguida de passagem de grade leve.
A semeadura das forrageiras foi realizada em novembro de 2009, com a utilização de $15 \mathrm{~kg}$ de sementes por hectare, com valor cultural de $36 \%$. As sementes foram distribuídas manualmente a lanço com posterior incorporação com grade leve acoplada ao trator.

Tabela 1. Características químicas na camada de $0-0,20 \mathrm{~m}$ do solo da área experimental

\begin{tabular}{|c|c|c|c|c|c|c|c|c|c|c|c|}
\hline$P$ & $\mathrm{MO}$ & $\mathrm{pH}$ & $\mathrm{Al}+\mathrm{H}$ & $\mathrm{Al}^{3+}$ & $\mathrm{K}^{+}$ & $\mathrm{Ca}^{2+}$ & $\mathrm{Mg}^{2+}$ & SB & CTC & V & Al \\
\hline $\mathrm{mg} \mathrm{dm}^{-3}$ & $\mathrm{~g} \mathrm{dm}^{-3}$ & $\mathrm{CaCl}_{2}$ & $\begin{array}{l}----- \\
----\end{array}$ & $-\ldots$ & 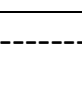 & $\mathrm{cmol}$ & & & 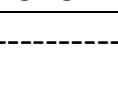 & $\%$ & $\%$ \\
\hline 7,75 & 27,34 & 4,48 & 7,76 & 0,25 & 0,37 & 3,22 & 1,81 & 5,40 & 13,16 & 41,03 & 4,42 \\
\hline
\end{tabular}

**Análises realizada no Laboratório de Química Ambiental e Instrumental da Unioeste, Campus Marechal Cândido Rondon, PR.

As plantas apresentaram desenvolvimento vegetativo satisfatório devido às condições de temperatura e precipitação favoráveis durante a fase de estabelecimento (Figura 1), de forma que aos 70 dias após a semeadura apresentavam-se estabelecidas na área e haviam atingido as alturas de pastejo recomendadas (SILVA; NASCIMENTO JUNIOR, 2007), permitindo o início dos pastejos. Os pastejos foram realizados por blocos, e foram utilizadas vacas da raça Holandesa, em lactação, com peso vivo aproximado de $550 \mathrm{~kg} \pm 28,5 \mathrm{~kg}$. Para a obtenção da altura de resíduo desejada $(0,15 \mathrm{~m})$, utilizou-se a técnica putand-take (MOTT; LUCAS, 1952), na qual, a carga de lotação animal era ajustada segundo a disponibilidade de forragem. Os animais foram mantidos nas parcelas até a obtenção de altura de resíduo desejada para todas as forrageiras. Com a obtenção da altura de resíduo desejada, os animais foram retirados, e a área foi vedada por um período de 40 dias, após o qual foi realizado o segundo pastejo seguindo os mesmos critérios adotados para o primeiro pastejo. O período de pastejo adotado foi de dois dias, simulando o pastejo rotacionado intensivo.

As amostragens para as avaliações foram realizadas antes de cada pastejo, aos 47 e 87 DAS para ao primeiro e segundo períodos de avaliação, respectivamente. Para as amostragens foi utilizado um quadrado de ferro com área conhecida $\left(0,25 \mathrm{~m}^{2}\right)$ que foi jogado aleatoriamente uma vez em cada parcela e todas as plantas contidas no seu interior foram cortadas com auxílio de cutelo e acondicionadas em sacos plásticos identificados. As amostras coletadas foram pesadas em balança de precisão para a 
determinação da produção de matéria verde (MV), com posterior separação em duas subamostras. A primeira foi destinada à determinação do teor de matéria seca (MS), enquanto a segunda foi separada em lâminas foliares e colmos+bainhas. Todas as amostras foram acondicionadas em sacos de papel identificados e conduzidas à estufa com circulação forçada de ar a $65 \pm 5$ 으, por 96 horas para secagem. Foram tomados os pesos dos sacos de papel e das amostras anterior e posteriormente à secagem para a determinação do teor de MS parcial. A produção de MS total, MS de folhas e MS de colmos foi obtida a partir da produção de MV e dos teores de MS. A relação folha/colmo (F/C) foi obtida através da razão entre o peso seco das lâminas foliares e o peso seco dos colmos+bainhas.

Para as avaliações das características estruturais, foram escolhidos ao acaso 10 perfilhos de cada amostra para a determinação do número de folhas por perfilho (NFP), comprimento de colmo (CC), diâmetro do colmo (DC) e comprimento de folhas (CF). O NFP foi determinado por meio de contagem manual das folhas sem sinais de senescência pertencentes à cada perfilho, enquanto $O D C$ foi mensurado na base de cada perfilho com auxílio de paquímetro digital e os CC e CF foram mensurados com auxílio de régua graduada em centímetros.

Para determinação da composição químico-bromatológica, após a secagem para determinação dos teores de MS, as amostras secas foram moídas em moinho tipo Willey, com peneira de 30 mesh, e armazenadas em sacos plásticos devidamente identificados. Foram determinados através de procedimentos laboratoriais os teores de proteína bruta (PB) segundo a Aoac (1990), fibra em detergente neutro (FDN), fibra em detergente ácido (FDA) e hemicelulose conforme Silva e Queiroz (2006).

Os resultados obtidos foram submetidos à análise de variância. As médias foram comparadas pelo teste Tukey, ao nível de $5 \%$ de probabilidade.

\section{RESULTADOS E DISCUSSÃO}

Na produção de matéria seca de folhas e colmos, nas proporções de ambos na forragem e na produção de matéria seca da parte aérea houve efeito significativo da interação dos fatores $(P<0,01)$ (Tabela 2$)$. 
Tabela 2. Resumo da análise de variância dos fatores biométricos avaliados.

\begin{tabular}{|c|c|c|c|c|c|c|c|c|c|c|c|c|}
\hline $\mathrm{FV}$ & $\begin{array}{l}\mathrm{G} \\
\mathrm{L}\end{array}$ & MSF & MSC & $\mathrm{FF}$ & CF & MST & ALT & DP & NFP & $D C$ & CFF & CFC \\
\hline B & 3 & $3,4^{\mathrm{ns}}$ & $2,91^{\mathrm{ns}}$ & $\underset{s}{0,18^{n}}$ & $0,2^{\mathrm{ns}}$ & $3,22^{\mathrm{ns}}$ & $1,4^{\mathrm{ns}}$ & $2,1^{\mathrm{ns}}$ & $0,9^{\mathrm{ns}}$ & $\begin{array}{c}1,0^{n} \\
s\end{array}$ & $1,3^{\mathrm{ns}}$ & $1,0^{\mathrm{ns}}$ \\
\hline$F$ & 3 & $\underset{*}{10,0 *}$ & $\begin{array}{c}28,17 \\
*\end{array}$ & $20,7^{*}$ & $\begin{array}{c}19,7 \\
*\end{array}$ & $6,25^{*}$ & $\begin{array}{c}41,9 \\
*\end{array}$ & $\begin{array}{c}21,8 \\
*\end{array}$ & $\begin{array}{c}13,1 \\
*\end{array}$ & $8,2^{*}$ & $55,7^{*}$ & $\begin{array}{c}18,9 \\
*\end{array}$ \\
\hline$C$ & 1 & $64,7^{*}$ & $\begin{array}{c}24,83 \\
*\end{array}$ & $8,1^{*}$ & $\begin{array}{c}6,62 \\
*\end{array}$ & $\underset{*}{122,2^{*}}$ & $7,7^{*}$ & $2,7^{*}$ & $0,8^{*}$ & $9,9 *$ & $0,17^{\mathrm{ns}}$ & $1,4^{\mathrm{ns}}$ \\
\hline $\mathrm{F}^{*} \mathrm{C}$ & 3 & $16,4^{*}$ & $9,87^{*}$ & $8,88^{*}$ & $\begin{array}{l}9,59 \\
*\end{array}$ & $6,9 *$ & $\begin{array}{c}2,98 \\
*\end{array}$ & $2,2^{*}$ & $6,9 *$ & $3,2^{*}$ & $17,6^{*}$ & $1,6^{*}$ \\
\hline $\begin{array}{c}\text { Err } \\
\mathrm{O}\end{array}$ & 21 & & & & & & & & & & & \\
\hline
\end{tabular}

Para o primeiro período de crescimento não foram observadas diferenças significativas entre a quantidade de matéria seca de folhas produzida pelas forrageiras, porém, no segundo período de crescimento, maior produção de matéria seca de folhas foi obtida com o capim Mombaça, seguido da $U$. ruzizensis, enquanto a U. brizantha cv. MG5 e o capim Áries apresentaram produções de matéria seca de folhas inferiores (Tabela 2). Os resultados eram esperados, e devem-se às características morfofisiológicas das forrageiras. O capim Mombaça, além de possuir maior comprimento de folhas que as demais gramíneas estudadas (Tabela 3), possui grande potencial para produção de matéria seca, com expressiva participação de folhas na forragem (MÜLLER et al., 2002), por apresentar baixa taxa de alongamento de colmo (RIBEIRO et al., 2009; SILVEIRA et al., 2010).

A produção de matéria seca de colmos foi superior na pastagem de $U$. brizantha $\mathrm{cv}$. MG5 no primeiro período de crescimento e inferior no capim Mombaça no segundo período de crescimento. Os resultados são inversos à produção de matéria seca de folhas, porém, coerentes e esperados. Tanto para a produção de matéria seca de folhas quanto de colmos, maior produção foi observada no segundo período de crescimento, culminando com maior produção de matéria seca total (Tabela 3).

As proporções de folhas e colmos na forragem foram diferentes entre as forrageiras no primeiro período de crescimento, com maior proporção de folhas na forragem produzida pela $U$. brizantha cv. MG5 em relação à $U$. ruziziensis e ao capim 
Áries, enquanto o capim Mombaça não diferiu das demais forrageiras (Tabela 3). No segundo período de crescimento, maior proporção de folhas foi observada na forragem produzida pela $U$. brizantha $\mathrm{cv}$. MG5 e pelo capim Mombaça. Para os colmos foi observado comportamento inverso, com maior proporção na forragem obtida com o capim Áries nos dois períodos de crescimento estudados, devido ao seu ciclo produtivo mais curto e sua entrada no estádio reprodutivo, que favorece o alongamento dos colmos (RIBEIRO et al., 2009). As diferenças observadas entre as forrageiras, e as alterações observadas do primeiro para o segundo período de crescimento eram esperadas, uma vez que a remoção da matéria seca de forragem pelo período de crescimento ou pastejo desencadeia mecanismos que promovem alterações morfológicas na parte aérea das plantas forrageiras (SBRISSIA et al., 2007). Além da duração e da intensidade do processo de desfolhação (SBRISSIA et al., 2007), as variações ocorrem também em função da espécie ou cultivar de forrageira em questão.

Tabela 3. Características produtivas das forrageiras tropicais: Urochloa ruziziensis, Urochloa brizantha cv. MG5 e Panicum maximum cvs. Áries e Mombaça em dois períodos de crescimento

\begin{tabular}{|c|c|c|c|c|}
\hline \multirow{2}{*}{ Tratamento } & \multicolumn{2}{|c|}{ MS de folhas $\left(\mathrm{kg} \mathrm{ha}^{-1}\right)$} & \multicolumn{2}{|c|}{ MS de colmos $\left(\mathrm{kg} \mathrm{ha}^{-1}\right)$} \\
\hline & 1ㅇ Período & 2o Período & 1ㅇ Período & 2o Período \\
\hline U. ruziziensis & $1648 \mathrm{aB}$ & 3179 bA & $1681 \mathrm{bB}$ & $3622 \mathrm{aA}$ \\
\hline U.b. cv. MG5 & $1838 \mathrm{aA}$ & 1939 cA & 2935 aA & 2937 aA \\
\hline Áries & $1151 \mathrm{aB}$ & 2016 cA & $1138 \mathrm{bB}$ & $2730 \mathrm{aA}$ \\
\hline Mombaça & $1107 \mathrm{aB}$ & 4858 aA & $977 \mathrm{bA}$ & $838 \mathrm{bA}$ \\
\hline CV1 (\%) & \multicolumn{2}{|c|}{32,44} & \multicolumn{2}{|c|}{18,51} \\
\hline CV2 (\%) & \multicolumn{2}{|c|}{23,23} & \multicolumn{2}{|c|}{23,51} \\
\hline
\end{tabular}

\begin{tabular}{|c|c|c|c|c|}
\hline & \multicolumn{2}{|c|}{ Folhas na forragem (\%) } & \multicolumn{2}{|c|}{ Colmos na forragem (\%) } \\
\hline & 10 Período & 2ㅇ Período & 10 Período & 2 Período \\
\hline U. ruziziensis & $49,49 \mathrm{bA}$ & $52,90 \mathrm{bA}$ & 50,50 aA & $47,09 \mathrm{abA}$ \\
\hline U. b. cv. MG5 & 67,21 aA & 69,88 aA & $32,78 \mathrm{bA}$ & $33,45 \mathrm{bA}$ \\
\hline Áries & $47,53 \mathrm{bA}$ & $41,26 \mathrm{bA}$ & $52,46 a A$ & 58,73 aA \\
\hline Mombaça & $53,37 \mathrm{abB}$ & $84,68 \mathrm{aA}$ & $46,62 \mathrm{abA}$ & $15,31 \mathrm{cB}$ \\
\hline CV1 (\%) & \multicolumn{2}{|c|}{12,56} & \multicolumn{2}{|c|}{18,43} \\
\hline \multirow[t]{3}{*}{ CV2 (\%) } & \multicolumn{2}{|c|}{13,37} & \multicolumn{2}{|c|}{18,07} \\
\hline & \multicolumn{4}{|c|}{ MS total $\left(\mathrm{kg} \mathrm{ha}^{-1}\right)$} \\
\hline & \multicolumn{2}{|c|}{ 1ㅇ Período } & \multicolumn{2}{|c|}{ 2o Período } \\
\hline U. ruziziensis & \multicolumn{2}{|c|}{$3329 a b B$} & \multicolumn{2}{|c|}{$6314, A$} \\
\hline$U$ & \multicolumn{2}{|c|}{3418 aA } & \multicolumn{2}{|c|}{$4275 \mathrm{cA}$} \\
\hline Áries & \multicolumn{2}{|c|}{$2289 a b B$} & \multicolumn{2}{|c|}{4746 bcA } \\
\hline Mombaça & \multicolumn{2}{|c|}{$2084 \mathrm{bB}$} & \multicolumn{2}{|c|}{$5696 \mathrm{abA}$} \\
\hline CV1 (\%) & \multicolumn{4}{|c|}{12,07} \\
\hline CV2 (\%) & \multicolumn{4}{|c|}{16,30} \\
\hline
\end{tabular}


A produção de matéria seca no primeiro período de crescimento foi superior na U. brizantha cv. MG5 em comparação ao capim Mombaça, mas ambos não diferiram do capim Áries e da U. ruziziensis, enquanto no segundo período de crescimento, maior produção foi obtida com a U. ruziziensis em relação à $U$. brizantha cV. MG5 e o capim Áries (Tabela 3). Os resultados evidenciam que apesar do grande potencial forrageiro das gramíneas do gênero Panicum (MINGOTTE et al., 2011), as gramíneas do gênero Urochloa também apresentam expressivo potencial forrageiro para Latossolos da região oeste do Paraná.

À exceção da U. brizantha cV. MG5, todas as demais apresentaram aumento na produção de matéria seca total do primeiro para o segundo período de crescimento, devido aos aumentos na produção de matéria seca de folhas e de colmos. Esse resultado deve-se ao estabelecimento das plantas na área experimental e às condições climáticas favoráveis após o primeiro período de crescimento (Figura 1), possibilitando o adequado desenvolvimento das plantas.

A altura de plantas, densidade de perfilhos, número de folhas por perfilho, diâmetro do colmo, comprimento final de folhas, distância entre nós e relação folha:colmo foram afetados pela interação dos fatores $(P<0,05)$, enquanto 0 comprimento final de colmo foi alterado somente pelas forrageiras $(P<0,01)$ (Tabela 2).

Tanto no primeiro quanto no segundo período de crescimento, a altura de plantas foi superior nas forrageiras do gênero Panicum (Tabela 4). Ao serem comparados os períodos de crescimento, apenas na $U$. ruziziensis foi observado um aumento na altura das plantas no segundo período de crescimento em relação ao primeiro. As diferenças observadas eram esperadas e se devem ao hábito de crescimento das forrageiras. Forrageiras do gênero Urochloa apresentam hábito de crescimento prostrado, enquanto as do gênero Panicum apresentam hábito de crescimento cespitoso (BOTREL et al., 1999; LEÃO et al., 2004).

Em se tratando da densidade de perfilhos, apesar de não ter diferido da $U$. brizantha cV. MG5 no primeiro período de crescimento, no segundo período de crescimento foi observado maior perfilhamento da $U$. ruziziensis (Tabela 4). Maior intensidade de perfilhamento das da U. ruziziensis já foi reportado na literatura (PACIULLO et al., 2011), e devem-se à sua capacidade de emissão de estolões com o enraizamento e emissão de novos perfilhos em cada nó. Esse processo foi favorecido pela presença dos animais em pastejo, que por meio do pisoteio favoreceram o contato dos estolões com o solo e o e o subsequente enraizamento. 
O número de folhas por perfilho foi superior nas forrageiras do gênero Panicum no primeiro período de crescimento, porém, no segundo período de crescimento, apenas o capim Áries apresentou número de folhas superior (Tabela 4). As forrageiras do gênero Panicum estudadas apresentaram comportamento inverso do primeiro para o segundo período de crescimento, de forma que ao mesmo tempo que o capim Mombaça reduziu o número de folhas por perfilho, o capim Áries apresentou aumento. O diâmetro do colmo diferenciou-se entre as forrageiras somente no segundo período de crescimento, apresentando redução do primeiro para o segundo período de crescimento e sendo inferior nos capins $U$. ruziziensis e Áries. Esse resultado está relacionado com o perfilhamento uma vez que existe relação inversa entre a densidade e o tamanho individual dos perfilhos (SBRISSIA; DA SILVA, 2008). Apesar de não ter sido estatisticamente significativo, o aumento na densidade de perfilhos nesses capins do primeiro para o segundo período de crescimento contribuiu para a redução no tamanho dos perfilhos, com consequente redução no seu diâmetro do colmo. Como segundo McMahom (1973), o diâmetro dos colmos altera-se em proporção direta à força requerida para suportar os demais órgãos das plantas (folhas), essa característica constitui-se um indicativo do tamanho dos perfilhos.

Os capins do gênero Panicum apresentaram comprimento final de folhas superior no primeiro período de crescimento, enquanto no segundo período de crescimento, apenas o capim Mombaça foi superior. À semelhança do ocorrido para o número de folhas por perfilho, ao serem comparados os períodos de crescimento houve comportamento inverso das forrageiras do gênero Panicum. Ao contrário do aumento no comprimento final de folhas do capim Mombaça, o capim Áries apresentou drástica redução, sem diferenças para as demais forrageiras (Tabela 4).

O comprimento final do colmo do capim Áries foi superior tanto no primeiro quanto no segundo período de crescimento, além de apresentar um aumento com o decorrer das avaliações (Tabela 6). Os resultados observados para o número de folhas por perfilhos, diâmetro do colmo, comprimento final de folhas e comprimento final do colmo do capim Áries, devem-se a sua entrada no estádio reprodutivo, com o alongamento do colmo e encurtamento das folhas à medida que se sucederam nos perfilhos. 
Tabela 4. Características estruturais das forrageiras tropicais Urochloa ruziziensis, Urochloa brizantha cv. MG5 e Panicum maximum cvs. Áries e Mombaça em dois períodos de crescimento

\begin{tabular}{|c|c|c|c|c|}
\hline \multirow[t]{2}{*}{ Tratamento } & \multicolumn{2}{|c|}{ Altura $(\mathrm{cm})$} & \multicolumn{2}{|c|}{ DP } \\
\hline & 10 Período & 2o Período & 10 Período & 20 Período \\
\hline U. ruziziensis & $47,25 \mathrm{bB}$ & $64,50 \mathrm{bA}$ & $123,25 a A$ & $150,00 a A$ \\
\hline U.b. cv. MG5 & $54,41 \mathrm{bA}$ & $62,25 \mathrm{bA}$ & $88,50 a b A$ & $71,50 \mathrm{bA}$ \\
\hline Áries & $86,50 a A$ & $86,00 a A$ & $82,00 \mathrm{bA}$ & $103,00 \mathrm{bA}$ \\
\hline Mombaça & $78,50 a A$ & $79,75 a A$ & $60,33 \mathrm{bA}$ & $72,66 \mathrm{bA}$ \\
\hline CV1 (\%) & \multicolumn{2}{|c|}{6,74} & \multicolumn{2}{|c|}{19,22} \\
\hline \multirow[t]{3}{*}{ CV2 (\%) } & \multicolumn{2}{|c|}{9,80} & \multicolumn{2}{|c|}{19,69} \\
\hline & \multicolumn{2}{|c|}{ NFP } & \multicolumn{2}{|c|}{$\mathrm{DC}(\mathrm{mm})$} \\
\hline & 1ㅇ Período & 2o Período & 1ㅇ Período & 2o Período \\
\hline U. ruziziensis & $3,00 \mathrm{abA}$ & $3,31 \mathrm{bA}$ & $3,32 \mathrm{aA}$ & $2,80 \mathrm{bB}$ \\
\hline U. b. cv. MG5 & 1,91bA & $2,33 \mathrm{bcA}$ & $3,71 \mathrm{aA}$ & $3,45 a A$ \\
\hline Áries & $3,20 a B$ & 4,41aA & $3,57 a A$ & $2,71 \mathrm{bB}$ \\
\hline Mombaça & $3,40 \mathrm{aA}$ & $2,15 c B$ & $3,68 \mathrm{aA}$ & $3,84 \mathrm{aA}$ \\
\hline CV1 (\%) & \multicolumn{2}{|c|}{8,44} & \multicolumn{2}{|c|}{15,77} \\
\hline \multirow[t]{3}{*}{ CV2 (\%) } & \multicolumn{2}{|c|}{19,86} & \multicolumn{2}{|c|}{8,50} \\
\hline & \multicolumn{2}{|c|}{$\mathrm{CFF}(\mathrm{cm})$} & \multicolumn{2}{|c|}{$\mathrm{CFC}(\mathrm{mm})$} \\
\hline & 1ㅇ Período & 2o Período & 1o Período & 2o Período \\
\hline U. ruziziensis & $29,35 b A$ & $26,90 \mathrm{bA}$ & $37,20 a A$ & $38,20 \mathrm{bA}$ \\
\hline U.b. cv. MG5 & $23,85 \mathrm{bA}$ & $28,22 \mathrm{bA}$ & $25,75 a b A$ & $30,35 \mathrm{bA}$ \\
\hline Áries & $47,10 a A$ & $26,72 b B$ & $42,86 a B$ & $60,83 a A$ \\
\hline Mombaça & $47,60 \mathrm{aB}$ & $63,03 a A$ & $15,00 \mathrm{bA}$ & $9,77 c A$ \\
\hline CV1 (\%) & \multicolumn{2}{|c|}{14,49} & \multicolumn{2}{|c|}{30,24} \\
\hline \multirow[t]{3}{*}{ CV2 (\%) } & \multicolumn{2}{|c|}{13,70} & \multicolumn{2}{|c|}{33,67} \\
\hline & \multicolumn{2}{|c|}{ Entre nós $(\mathrm{cm})$} & \multicolumn{2}{|c|}{ Relação F:C } \\
\hline & 1ㅇ Período & 2o Período & 10 Período & 2o Período \\
\hline U. ruziziensis & $14,20 \mathrm{aA}$ & $14,20 \mathrm{aA}$ & $0,98 a A$ & $0,87 c A$ \\
\hline U. b. cV. MG5 & $9,57 \mathrm{bA}$ & $9,57 \mathrm{bA}$ & $1,87 a A$ & $2,22 \mathrm{bA}$ \\
\hline Áries & $16,00 \mathrm{aA}$ & $16,00 \mathrm{aA}$ & $0,92 a A$ & $0,82 c A$ \\
\hline Mombaça & $0,00 \mathrm{cB}$ & $8,70 \mathrm{bA}$ & $1,14 a B$ & $5,89 a A$ \\
\hline CV1 (\%) & \multicolumn{2}{|c|}{2,33} & \multicolumn{2}{|c|}{39,76} \\
\hline CV2 (\%) & \multicolumn{2}{|c|}{13,76} & \multicolumn{2}{|c|}{36,14} \\
\hline \multicolumn{5}{|c|}{$\begin{array}{l}\text { *Valores seguidos de mesma letra maiúscula na linha e minúscula na coluna, não diferem entre si pelo teste Tukey a } \\
\text { 5\%. DP: densidade de perfilhos; NFP: número de folhas verdes por perfilho; DC: diâmetro de colmo; CFF: comprimento } \\
\text { final de folhas; CFC: comprimento final de colmo; EN: espaço entre nós; F:C: relação folha/colmo. CV1 (\%): coeficiente } \\
\text { de variação da parcela; CV2 (\%): coeficiente de variação da subparcela. }\end{array}$} \\
\hline
\end{tabular}

A maior distância entre nós no primeiro e segundo período de crescimento foi observada nos capins U. ruziziensis e Áries, enquanto o capim Mombaça apresentou entre-nós somente no segundo período de crescimento (Tabela 4). A relação folha/colmo foi semelhante em todas as forrageiras no primeiro período de crescimento, porém, superior no capim Mombaça no segundo período de crescimento. A grande proporção de folhas e o lento alongamento do colmo do capim Mombaça foram reportados por Ribeiro et al. (2009). Essas características são as principais responsáveis por proporcionar a essa forrageira um elevado valor nutritivo.

Em se tratando do valor nutritivo de forrageiras, estudos que caracterizam a composição química são relevantes na avaliação de forrageiras, pois auxiliam na 
indicação da necessidade de suplementação da dieta em determinadas épocas para algumas categorias de animais (VELAZQUES et al., 2010). O estudo do valor nutritivo da forragem possibilita ainda a identificação dos pontos restritivos do consumo de nutrientes e da produção animal (BRÂNCIO et al., 2002).
Para a PB houve efeito significativo da interação dos fatores $(p<0,05)$, enquanto a FDN, FDA e hemicelulose não foram alteradas pelos fatores estudados $(p>0,05)$ (Tabela 5).

Tabela 5. Resumo da análise de variância dos demais fatores biométricos e variáveis bioquímicas avaliadas

\begin{tabular}{cccccccc}
\hline FV & GL & EN & FC & PB & FDN & FDA & HEM \\
\hline B & 3 & $1,3^{\text {ns }}$ & $0,8^{\text {ns }}$ & $2,8^{\text {ns }}$ & $0,3^{\text {ns }}$ & $1,4^{\text {ns }}$ & $0,4^{\text {ns }}$ \\
F & 3 & $109,4^{*}$ & $27,0^{*}$ & $16,1^{*}$ & $2,3^{\text {ns }}$ & $6,6^{\text {ns }}$ & $0,5^{\text {ns }}$ \\
C & 1 & $19,1^{*}$ & $26,0^{*}$ & $27,7^{*}$ & $4,2^{\text {ns }}$ & $15,7^{\text {ns }}$ & $0,2^{\text {ns }}$ \\
$F^{*} C$ & 3 & $19,1^{*}$ & $24,3^{*}$ & $7,8^{*}$ & $2,5^{\text {ns }}$ & $9,6^{\text {ns }}$ & $0,9^{\text {ns }}$ \\
Erro & 21 & & & & & &
\end{tabular}

\footnotetext{
${ }^{\mathrm{ns}}$ não significativo pelo teste $\mathrm{F}$ a $1 \%$ de probabilidade. ${ }^{*}$ significativo pelo teste $\mathrm{F}$ a $1 \%$ de probabilidade. B: bloco; $\mathrm{F}$ : forrageiras; C: cortes; $F^{*} C$ : interação forrageiras e cortes; EN: espaço entre nós; $F$ :C: relação folha/colmo; PB: proteína bruta (\%); FDN: fibra em detergente neutro (\%); FDA: fibra em detergente ácido (\%); HEM: hemicelulose (\%).
}

Os teores de proteína bruta foram superiores nas forrageiras no gênero Panicum no primeiro período de crescimento, e superiores apenas no capim Mombaça no segundo período de crescimento (Tabela 6). Apenas os capins $U$. brizantha cv. MG5 e Áries apresentaram redução nos teores de proteína bruta do primeiro para o segundo período de crescimento. O declínio do valor nutritivo está relacionado com o avanço no estádio fisiológico (CANO et al., 2004) e com a maturidade das plantas (SOARES FILHO et al., 2002). Ao atingir o estádio reprodutivo, o capim Áries apresentava colmos mais velhos e mais lignificados, com consequente redução das concentrações de proteína bruta na matéria seca (VAN SOEST, 1994).

Tabela 6. Composição Bromatológica das forrageiras tropicais Urochloa ruziziensis, Urochloa brizantha cv. MG5 e Panicum maximum cvs. Áries e Mombaça em dois períodos de crescimento

\begin{tabular}{|c|c|c|c|c|}
\hline \multirow{2}{*}{ Tratamento } & \multicolumn{2}{|c|}{ PB (\%) } & \multicolumn{2}{|c|}{ FDN (\%) } \\
\hline & 1ㅇ Período & 2o Período & 1ㅇ Período & 2o Período \\
\hline U. ruziziensis & $11,52 \mathrm{bA}$ & $12,03 \mathrm{bA}$ & 69,63 & 77,23 \\
\hline U. b. cv. MG5 & 13,66 aA & $11,44 \mathrm{bB}$ & 74,67 & 73,56 \\
\hline Áries & $15,88 \mathrm{aA}$ & $11,28 \mathrm{bB}$ & 76,12 & 79,06 \\
\hline Mombaça & 16,47 aA & $14,88 \mathrm{aA}$ & 74,37 & 74,77 \\
\hline CV1 (\%) & \multicolumn{2}{|c|}{10,66} & \multicolumn{2}{|c|}{3,85} \\
\hline CV2 (\%) & \multicolumn{2}{|c|}{7,10} & \multicolumn{2}{|c|}{4,61} \\
\hline
\end{tabular}




\begin{tabular}{|c|c|c|c|c|}
\hline & \multicolumn{2}{|c|}{ FDA (\%) } & \multicolumn{2}{|c|}{ Hemicelulose (\%) } \\
\hline & 10 Período & 20 Período & 1ㅇ Período & 2ㅇ Período \\
\hline U. ruziziensis & 37,89 & 43,45 & 31,74 & 33,92 \\
\hline U.b. cv. MG5 & 40,45 & 42,29 & 34,21 & 34,38 \\
\hline Áries & 40,53 & 45,31 & 35,59 & 33,74 \\
\hline Mombaça & 39,16 & 44,18 & 35,22 & 32,66 \\
\hline CV1 (\%) & \multicolumn{2}{|c|}{7,27} & \multicolumn{2}{|c|}{4,12} \\
\hline CV2 (\%) & \multicolumn{2}{|c|}{9,90} & \multicolumn{2}{|c|}{12,76} \\
\hline
\end{tabular}

*Valores seguidos de mesma letra maiúscula na linha e minúscula na coluna, não diferem entre si pelo teste Tukey a 5\%. PB: proteína bruta; FDN: fibra insolúvel em detergente neutro; FDA: fibra insolúvel em detergente ácido; MM: matéria mineral; MO: matéria orgânica. CV1 (\%): coeficiente de variação da parcela; CV2 (\%): coeficiente de variação da subparcela.

Os valores de FDN não foram alterados pelos fatores estudados, porém nas concentrações de FDA, se elevaram do primeiro para o segundo período de crescimento em todas as forrageiras estudadas (Tabela 6). Esse resultado deve-se ao avanço na idade de desenvolvimento das plantas, pois mesmo com a realização do pastejo com altura constante, após este o alongamento das frações mais velhas dos colmos foi possibilitada, e eles passaram a fazer parte da forragem amostrada no segundo período de crescimento, contribuindo para a redução do seu valor nutritivo. Apesar de os colmos não se fazerem presentes em quantidade suficiente para reduzir a relação folha/colmo da forragem (Tabela 4), por se apresentarem com idade avançada, e com aspecto visual de altamente lignificados, foram capazes de alterar as concentrações de FDA na forragem.

À medida que as plantas forrageiras crescem, ocorre uma elevação nas concentrações dos compostos estruturais
(ZANINE; MACEDO JUNIOR, 2006), como celulose e lignina, reduzindo o conteúdo celular e a proporção dos nutrientes potencialmente digestíveis (carboidratos solúveis, proteínas, minerais e vitaminas) (REIS et al., 2005). Essa redução causa uma queda acentuada na digestibilidade da forragem, uma vez que a digestibilidade apresenta correlação negativa com os constituintes fibrosos da forragem (ALVES DE BRITO et al., 2003).

\section{CONCLUSÕES}

As variáveis biométricas no geral não foram afetadas pelo manejo de um corte adotado, apresentando diferenças apenas entre si.

Os valores de proteína bruta, apresentaram apenas variação entre cortes para a forrageira Urochloa brizantha. cv. MG5 e Panicum maximum cv. Áries.

Os teores de FDN. FDA e Hemicelulose, não foram afetados pelo manejo com cortes 
e não apresentaram variações entre si dessas variáveis.

Em pastagens manejadas sob pastejo com intervalos de 40 dias, o capim Mombaça apresenta elevada produção de forragem com maior proporção de folhas, reduzido alongamento de colmos, e teor de proteína bruta superior.

O manejo com dois cortes se mostrou adequado nas condições experimentais testadas, podendo ser utilizada a nível de campo, com satisfatório rendimento.

\section{REFERÊNCIAS}

ALVES DE BRITO, C.J.F.; RODELLA, R.A.; DESCHAMPS, F.C. Perfil químico da parede celular e suas implicações na digestibilidade de Brachiaria brizantha e Brachiaria humidicola. Revista Brasileira de Zootecnia, Viçosa, v.32, n.8, p.1835-1844, ago. 2003. http://dx.doi.org/10.1590/S151635982003000800005

AOAC. ASSOCIATION OF OFFICIAL ANALYTICAL CHEMISTS. Official methods of analysis. 15. ed. Virginia: Arlington, 1990. $1117 p$.

BOTREL, M.A.; ALVIM, M.J.; XAVIER, D.F. Avaliação de gramíneas forrageiras na região sul de Minas Gerais. Pesquisa Agropecuária Brasileira, Brasília, v.34, n.4, p.683-689, abr. 1999. http://dx.doi.org/10.1590/S0100204X1999000400021

BRÂNCIO, P.A.; NASCIMENTO JR., D.; EUCLIDES, V.P.B.; REGAZZI, A.J.; ALMEIDA, R.G.; FONSECA. D.M.; BARBOSA, R.A. Avaliação de três cultivares de Panicum maximum Jacq. sob pastejo. composição química e digestibilidade da forragem.
Revista Brasileira de Zootecnia, Viçosa, v.31, n.4, p.1605-1613, abr. 2002. http://dx.doi.org/10.1590/S151635982002000700002

CANO, C.C.P.; CANTO, M.W.; SANTOS, G.T.; GALBEIRO, S. MARTINS, E.N.; MIRA, R.T. Valor nutritivo do capim-Tanzânia (Panicum maximum Jacq. cv. Tanzânia-1) pastejado em diferentes alturas. Revista Brasileira de Zootecnia, Viçosa, v.33, n.6, supl.2, p. 19591968, dez. 2004. http://dx.doi.org/10.1590/S151635982004000800006

DIFANTE, G.S.; NASCIMENTO JUNIOR, D.; SILVA, S.C.; EUCLIDES, V.P.B.; MONTAGNER, D.B.; SILVEIRA, M.C.T.; PENA, K.S. Características morfogênicas e estruturais do capim-marandu submetido a combinações de alturas e intervalos de corte. Revista Brasileira de Zootecnia, Viçosa, v.40, n.5, p.955-963, mai. 2011. http://dx.doi.org/10.1590/S151635982011000500003

EMBRAPA. Empresa Brasileira de Pesquisa Agropecuária. Sistema brasileira de classificação de solos. 2. ed. Rio de Janeiro: EMBRAPA Solos, 2006. 306p.

LEÃO, T.P.; SILVA, A.P.; MACEDO, M.C.M.; IMHOFF, S.; EUCLIDES, V.P.B. Intervalo hídrico ótimo na avaliação de sistemas de pastejo contínuo e rotacionado. Revista Brasileira de Ciência do Solo, Viçosa, v. 28, p. 415-423, 2004. http://dx.doi.org/10.1590/S010006832004000300002

McMAHOM, C. Size and shape in biology. Science, Washington, n. 1, v.179, p.12011204, jan./jun. 1973.

MINGOTTE, F.L.C.; SANTOS, C.L.R.; PRADO, R.M.; FLORES, R.A.; TOGORO, A.H.; SILVA, J.A.S.; POLIT, L.S.; PINTO, A.S.; AQUINO, D.S. Manganês na nutrição e na produção de 
massa seca do capim-mombaça. Bioscience Journal, Uberlândia, v. 27, n. 6, p.879-887, nov./dez. 2011.

MOTT, G.E.; LUCAS, H.L. The design, conduct en interpretation of grazing trials on cultivated and improved pastures. In: INTERNATIONAL GRASSLAND CONGRESS, 6., 1952, Pensilvania, Proceedings ... Pensilvania: State College, 1952. p.1380-1395.

MULLER, M.S.; FANCELLI, A.L.; DOURADONETO, D.; GARCÍA, A.G.; OVEREJO, R.F.L. Produtividade do Panicum maximum cV. Mombaça Irrigado, sob pastejo rotacionado. Scientia Agricola, Piracicaba, v.59, n.3, p.427433, jul./set. 2002. http://dx.doi.org/10.1590/S010390162002000300003

PACIULLO, D.S.; GOMIDE, C.A.M.; CASTRO, C.R.T.; FERNANDES, P.B.; MULLER, M.D.; PIRES, M.F.A.P.; FERNANDES, E.N.; XAVIER, D.F. Características produtivas e nutricionais do pasto em sistema agrossilvipastoril, conforme a distância das árvores. Pesquisa Agropecuária Brasileira, Brasília, v.46, n.10, p.1176-1183, out. 2011. http://dx.doi.org/10.1590/s0100-

204X2011001000009

REIS, R.A.; MELO G.M.P.; BERTIPAGLIA L.M.A. Otimização da utilização da forragem disponível através da suplementação estratégica. In: REIS R.A.; SIQUEIRA, G.R.; BERTIPAGLIA, L.M.A. et al. (Eds). Volumosos na produção de ruminantes. Jaboticabal: Funep, 2005. p.187-238.

RIBEIRO, E.G.; FONTES, C.A.A.; PALIERAQUI, J.G.B.; COSER, A.C.; MARTINS, C.E.; SILVA, R.C. Influência da irrigação, nas épocas seca e chuvosa, na produção e composição química dos capins Napier e Mombaça em sistema de lotação intermitente. Revista Brasileira de Zootecnia, Viçosa, v.38, n.8, p.1432-1442, ago. 2009. http://dx.doi.org/10.1590/S151635982009000800006
SBRISSIA, A.F.; DA SILVA, S.C.; NASCIMENTO JÚNIOR, D. Ecofisiologia de plantas forrageiras e o manejo do pastejo. In: SIMPÓSIO SOBRE MANEJO DA PASTAGEM, 24., 2007, Piracicaba. Anais... Piracicaba: FEALQ, 2007. p.153-176.

SBRISSIA, A.F.; DA SILVA, S.C. Compensação tamanho/densidade populacional de perfilhos em pastos de capim-marandu. Revista Brasileira de Zootecnia, Viçosa, v.37, n.1, p.35-47, jan. 2008. http://dx.doi.org/10.1590/S151635982008000100005

SILVA, D.J.; QUEIROZ, A.C. Análise de alimentos: métodos químicos e biológicos. Viçosa: Ed. UFV, 2006. 235 p.

SILVA, S.C.; NASCIMENTO JUNIOR, D. Avanços na pesquisa com plantas forrageiras tropicais em pastagens: características morfofisiológicas e manejo do pastejo. Revista Brasileira de Zootecnia, Viçosa, v.36, suppl., p.122-138, dez. 2007. http://dx.doi.org/10.1590/S151635982007001000014

SILVA, C.F. Manual de análises químicas de solos, plantas e fertilizantes. Brasília: EMBRAPA Informação Tecnológica, 2009. $627 p$.

SILVEIRA, M.C.T.; NASCIMENTO JÚNIOR, D.; SILVA, S.C.; EUCLIDES, V.P.B.; MONTAGNER, D.B.; SBRISSIA, A.F.; RODRIGUES, C.S.; SOUZA, B.M.L.; PENA, K.S.; VILELA, H.H. Morphogenetic and structural comparative characterization of tropical forage grass cultivars under free growth. Scientia Agricola, Piracicaba, v.67, n.2, p.136-142, abr. 2010. http://dx.doi.org/10.1590/S010390162010000200002

SKONIESKI, F.R.; VIÉGAS, J.; BERMUDES, R.F.; NÖRNBERG, J.L.; ZIECH, M.F.; COSTA, O.A.D.; MEINERZ, G.R. Composição botânica e estrutural e valor nutricional de pastagens de 
azevém consorciadas. Revista Brasileira de Zootecnia, Viçosa, v.40, n.3, p.550-556, mar. 2011. http://dx.doi.org/10.1590/S151635982011000300012

SOARES FILHO, C.V.; RODRIGUES, L.R.A.; PERRI, S.H.V. Produção e valor nutritivo de dez gramíneas forrageiras na região noroeste do estado de São Paulo. Acta Scientiarum, Maringá, v.24, n.5, p.1377-1384, out./dez. 2002.

VAN SOEST, P.J. Nutritional ecology of the ruminant. Ithaca: Constock Publishing Associates, 1994. $476 \mathrm{p}$.

VELASQUEZ, P.A.T.; BERCHIELLI, T.T.; REIS, R.A.; RIVERA, A.R.; DIAN, P.H.M.; TEIXEIRA, I.A.M.A. Composição química, fracionamento de carboidratos e proteínas e digestibilidade in vitro de forrageiras tropicais em diferentes idades de corte. Revista Brasileira de Zootecnia, Viçosa, v.39, n.6, p.1206-1213, jun. 2010. http://dx.doi.org/10.1590/S151635982010000600007

VIANA, M.C.M.; FREIRE, F.M.; FERREIRA, J.J.; MACÊDO, G.A.R.; CANTARUTTI, R.B.; MASCARENHAS, M.H.T. Adubação nitrogenada na produção e composição química do capim-braquiária sob pastejo rotacionado. Revista Brasileira de Zootecnia, Viçosa, v.40, n.7, p.1497-1503, jul. 2011. http://dx.doi.org/10.1590/S151635982011000700014

ZANINE, A.M.; MACEDO JÚNIOR, G.L. Importância do consumo da fibra para nutrição de ruminantes. Revista Eletrónica de Veterinária, Málaga, v.7, n.4, p.1-12, abr. 2006.

Recebido para publicação em 29/06/2013

Revisado em 12/12/2013

Aceito em 18/02/2014 